Supporting Information

\title{
Lamellar Lyotropic Liquid Crystal Superior to Micellar Solution for Proton Conduction in an Aqueous Solution of 1-Tetradecyl-3- methylimidazolium Hydrogen Sulfate
}

Jie Luo, Jie You, Shuai Tan, Caihong Wang, Yong Wu*

School of Chemical Engineering, Sichuan University

No. 24 South Section 1, Yihuan Road, Chengdu 610065, China

Corresponding Author

*E-mail: wuyong@scu.edu.cn 


\section{2D ${ }^{1} \mathrm{H}-\mathrm{NMR}$ spectra}
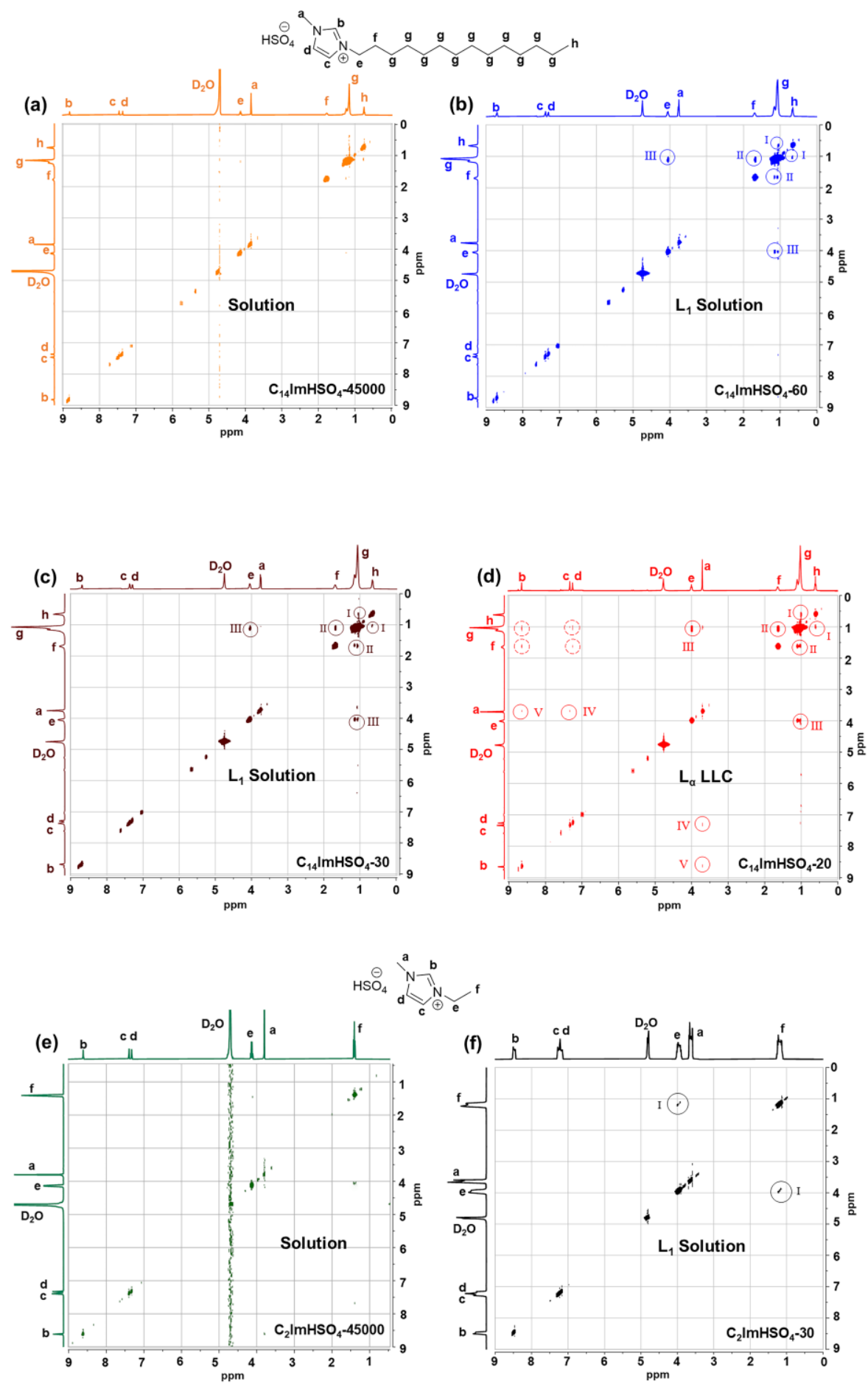

Figure S1. 2D ${ }^{1} \mathrm{H}-\mathrm{NMR}$ spectra of $\mathrm{C}_{14} \mathrm{ImHSO}_{4}-4500$ (a), $\mathrm{C}_{14} \mathrm{ImHSO}_{4}-60$ (b), $\mathrm{C}_{14} \mathrm{ImHSO}_{4}-30$ (c), $\mathrm{C}_{14} \mathrm{ImHSO}_{4}-20$ (d), $\mathrm{C}_{2} \mathrm{ImHSO}_{4}-4500$ (e) and $\mathrm{C}_{2} \mathrm{ImHSO}_{4}-30$ (f) recorded in $\mathrm{D}_{2} \mathrm{O}$. 


\section{Calculation of $d_{L}$ and $d_{W}$ of $\mathrm{C}_{14} \mathrm{ImHSO}_{4-20}$ and $\mathrm{C}_{14} \mathrm{ImHSO}_{4}-9$}

The layer spacing $(d)$ of the lamellar phase is obtained according to Eq. (S-1) ${ }^{1}$.

$$
d=\frac{\lambda \cdot l}{2 \sin \theta}
$$

where $\lambda, l$ and $\theta$ are wavelength of the incident X-ray beam $(0.154 \mathrm{~nm})$, Miller index and half of the diffraction angle, respectively.

The volume fraction $\left(\phi_{S}\right)$ of $\left[\mathrm{C}_{14} \mathrm{MIm}\right]\left[\mathrm{HSO}_{4}\right]$ in binary mixtures is calculated by Eq. $(\mathrm{S}-2)^{2}$.

$$
\phi_{S}=\frac{\frac{W_{S}}{\rho_{S}}}{\frac{W_{S}}{\rho_{S}}+\frac{W_{W}}{\rho_{W}}}
$$

where $W_{S}$ and $W_{W}$ are the weight fractions of $\left[\mathrm{C}_{14} \mathrm{MIm}\right]\left[\mathrm{HSO}_{4}\right]$ and water, respectively. $\rho_{S}$ and $\rho_{W}$ are the densities of $\left[\mathrm{C}_{14} \mathrm{MIm}_{[}\left[\mathrm{HSO}_{4}\right]\left(1.38 \mathrm{~g} \mathrm{~cm}^{-3}\right)\right.$ and water $\left(1 \mathrm{~g} \mathrm{~cm}^{-3}\right)$, respectively.

The thickness of hydrophobic layer $\left(d_{L}\right)$ in the $L_{\mathrm{a}}$ phase is obtained as Eq. $(\mathrm{S}-3)^{2}$.

$$
d_{L}=\phi_{S} \cdot d
$$

Furthermore, the thickness of water layer $\left(d_{W}\right)$ in the $L_{\mathrm{a}}$ phase is given by Eq. (S-4).

$$
d_{W}=d-d_{L}
$$

Table S1. Structure parameters for the $\mathrm{C}_{14} \mathrm{ImHSO}_{4}-20$ and $\mathrm{C}_{14} \mathrm{ImHSO}_{4}-9$ at $25^{\circ} \mathrm{C}$.

\begin{tabular}{lccccc}
\hline $\mathrm{C}_{14} \mathrm{ImHSO}_{4}-w_{0}$ & Phase & $d(\mathrm{~nm})$ & $\phi_{S}$ & $d_{L}(\mathrm{~nm})$ & $d_{W}(\mathrm{~nm})$ \\
\hline $\mathrm{C}_{14} \mathrm{ImHSO}_{4}-20$ & $L_{\mathrm{a}}$ & 4.16 & 0.4207 & 1.75 & 2.41 \\
$\mathrm{C}_{14} \mathrm{ImHSO}_{4}-9$ & $L_{\mathrm{a}}$ & 3.97 & 0.6272 & 2.49 & 1.48 \\
\hline
\end{tabular}




\section{EIS impedance spectra}
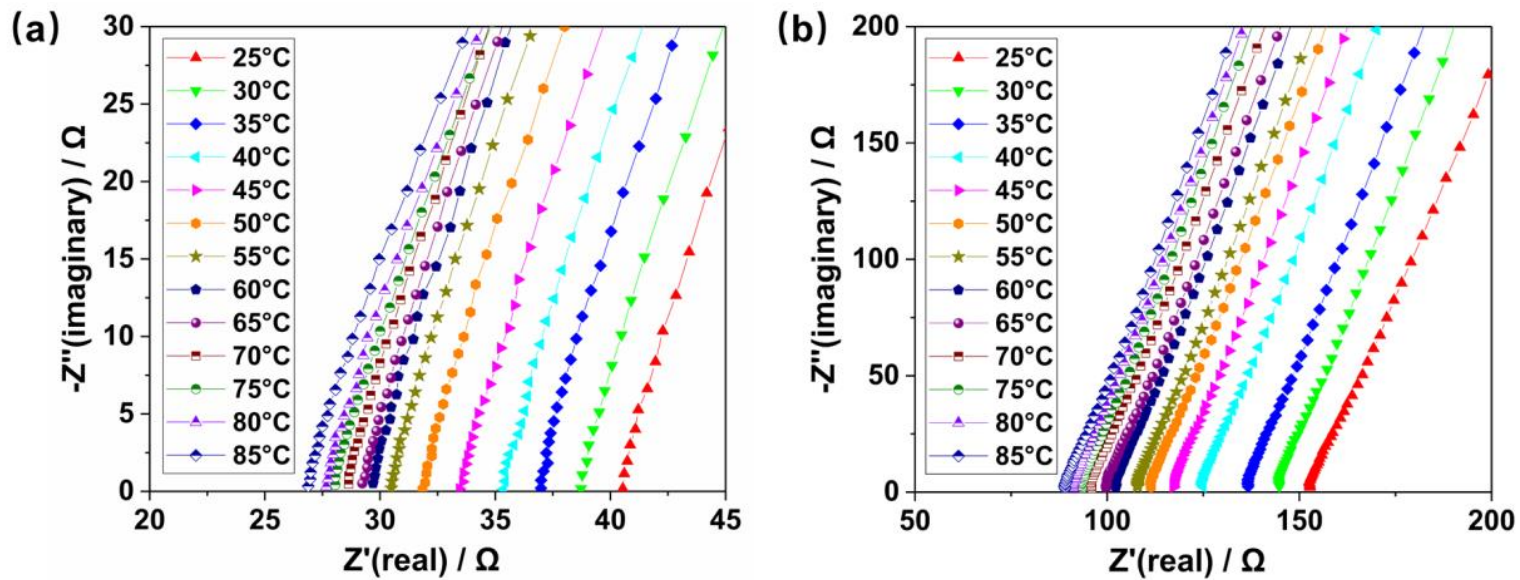

Figure S2. Impedance spectra of $\mathrm{C}_{14} \mathrm{ImHSO}_{4}-20$ (a) and $\mathrm{C}_{2} \mathrm{ImHSO}_{4}-20$ (b) at different temperatures.

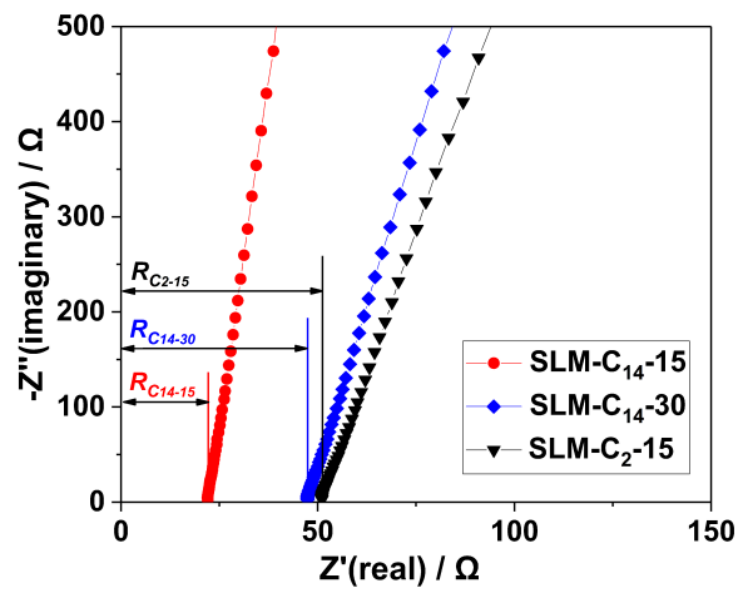

Figure S3. Impedance spectra of SLM-C $1_{14}-15$, SLM-C $14-30$ and SLM-C ${ }_{2}-15$ at $25^{\circ} \mathrm{C}$. 


\section{Temperature-dependent conductivities}

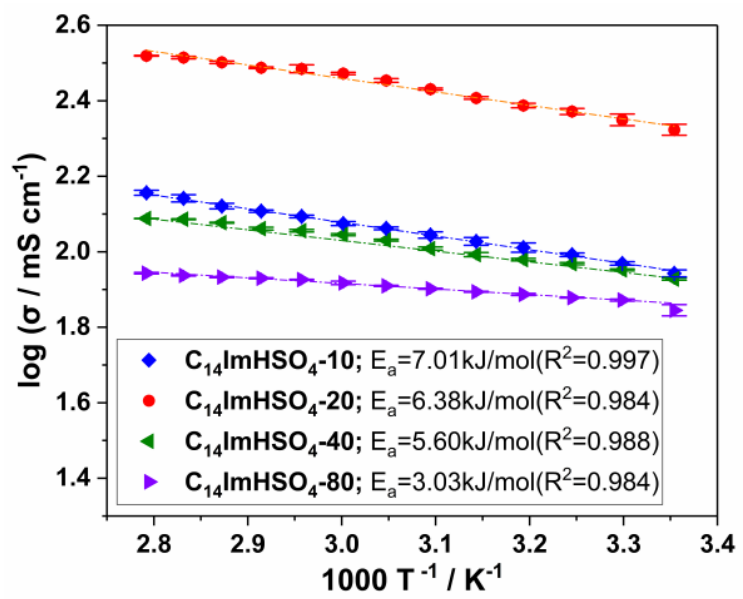

Figure S4. Temperature-dependent conductivities of $\mathrm{C}_{14} \mathrm{ImHSO}_{4}-w_{0}$ (Dot lines are Arrhenius fitting of conductivities).

\section{References}

(S1) Bragg, W. H.; Bragg, W. L. The Reflection of X-rays by Crystals. Proc. R. Soc. London. A. $1913,88,428-438$.

(S2) Shi, L.; Zhao, M.; Zheng, L. Lyotropic Liquid Crystalline Phases Formed in Ternary Mixtures of N-alkyl-N-Methylpyrrolidinium Bromide/1-Decanol/Water. RSC Advances. 2012, 2, 1192211929. 